\title{
Evaluation of Interaction Between Flat Car and Container at Dynamic Coupling of Flat Cars
}

\author{
Andrew Nikitchenko ${ }^{1}$, Viktor Artiukh ${ }^{2,}$, Denis Shevchenko ${ }^{1}$ and Raghu Prakash $^{3}$ \\ ${ }^{1}$ All-Union Research and Development Centre for Transportation Technology, 23 line Vasilievsky \\ Island, 2, Saint-Petersburg, 199106, Russia \\ ${ }^{2}$ Peter the Great St. Petersburg Polytechnic University, Polytechnicheskaya, 29, Saint-Petersburg, \\ 195251, Russia \\ ${ }^{3}$ Indian Institute of Technology Madras, C1-6-7, Second Loop Road, Madras Campus, Chennai, \\ 600036, India
}

\begin{abstract}
Innovative materials and structures are analyzed in this paper. To calculate the strength of the collision of flat wagons for the transport of large containers, there is no clear methodology for determining effort interaction between the container and the platform. At high longitudinal acceleration of the container, it is set in motion, and the consideration of this problem in a static setting impossible. The relevance of this work is to develop a methodology that is based on the equations of motion and considers dynamic interaction between container and platform.
\end{abstract}

\section{Introduction}

There are different approaches to strength analysis of the flat cars intended for transportation of large-capacity containers, in particular, in what concerns evaluation of interaction between container and platform. The matter is that at large longitudinal accelerations the container may start moving and, respectively, the static scheme of analysis can not by applied [1]. Some specifications, e.g. [2], recommend to consider the dynamic effects of interaction by applying a vertical component of inertia force approximated by $50 \%$ of the longitudinal inertia of container which in principle, is incorrect [3-5].

\section{Materials and Methods}

The present analysis is focused on development of a technique which is based on formulation of relevant motion equations and considers dynamic interaction between container and platform [6-8].

The vertical component of the longitudinal inertia force acting on the container according to the scheme of Fig. 1 is defined as

\footnotetext{
* Corresponding author: artiukh@mail.ru
} 


$$
R=m_{k} a_{x} \frac{h}{2 L}
$$

The total dynamic interaction of container and flat-car, respectively, is defined as:

- the dynamic force applied to fitting in direction of the flat-car loading:

$$
R Y_{1}=\frac{m_{K} g}{2}+\frac{m_{K} a_{x}}{2} \cdot \frac{h}{L}=\frac{m_{K}}{2}\left(g+a_{x} \frac{h}{L}\right)
$$

- and from the opposite side,

$$
R Y_{2}=\frac{m_{K}}{2}\left(g-a_{x} \frac{h}{L}\right)
$$

The scheme of inertia loads on a container (Fig.1)

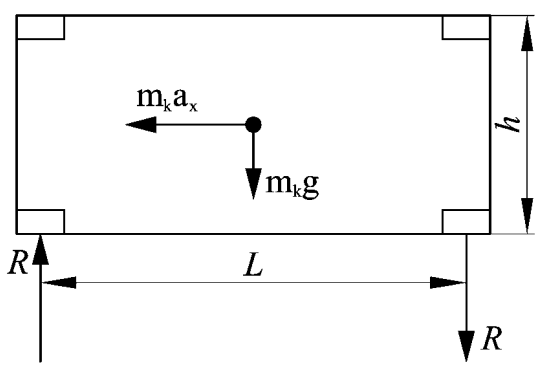

Fig. 1. Scheme of inertia loads on a container.

where $a_{x}$ is the longitudinal acceleration of the container; when an only one container is installed on the flat car, the longitudinal acceleration is find by

$$
a_{x}=\frac{P}{m_{\Pi}+m_{K}}
$$

where $P$ is the longitudinal load transferred through the automatic coupling, $m_{\Pi}-$ the mass of the flat car.

Substitution of (Eq. 4) into (Eq. 2) allows defining the vertical component of interaction between fitting of the container and the flat car:

$$
R Y_{1}=\frac{m_{K}}{2}\left(g+\frac{P}{m_{\Pi}+m_{K}} \cdot \frac{h}{L}\right)
$$

As follows from (Eq. 3) at longitudinal acceleration $a_{x}>g h / L$ the inertia load between fitting of the container and the flat car from outside, opposite to the direction of dynamic force caused by coupling of cars, becomes negative. If the container were fixed on the flat car the vertical direction, then formulae (Eq. 2) and (Eq. 3) would be true. However, since the fittings do not prevent vertical displacement of the container it is readily feasible 
that under dynamic coupling of cars the container would rotate around the fitting as shown in the scheme Fig. 2. At the same time, the interaction of the container and the flat car has to be obtained, specifically since it is necessary for the stress analysis [9-12] of the car structure.

To solve the problem of behavior of the system of rigid bodies loaded due to the dynamic automatic coupling of cars, Fig. 2, is considered.

The assumed system has two degrees of freedom: movement along the axis $\mathrm{x}$ and rotation, $\varphi$. Equations of motion of the system:

$$
\frac{d}{d t}\left(\frac{\partial T}{\partial \dot{q}_{i}}\right)-\frac{\partial T}{\partial q_{i}}=Q_{q i},
$$

where $T$ is the kinetic energy of system, $q_{i}$ are generalized coordinates, $Q_{q i}$ is the generalized external forces corresponding to $q_{i}$ coordinate.

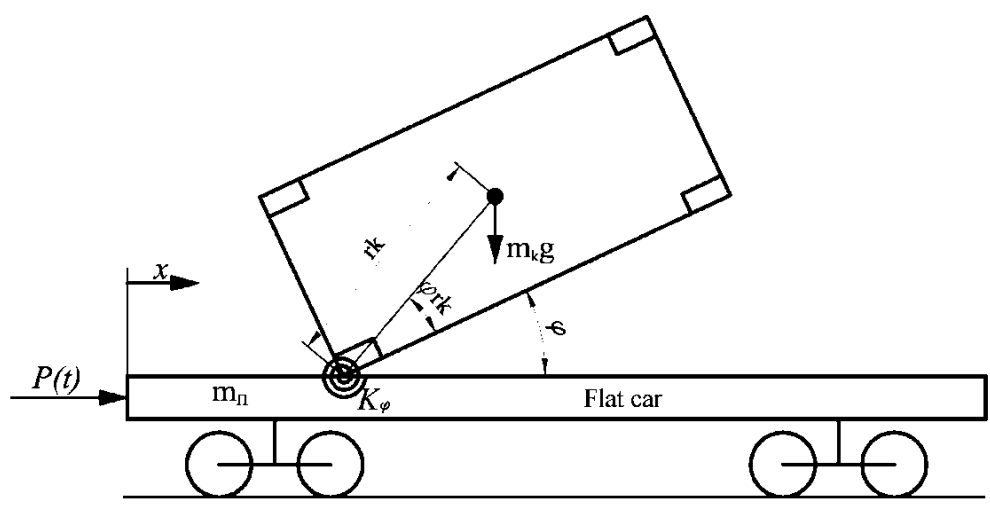

Fig. 2. The scheme of the mechanical system consisting of flat car and container

Kinetic energy $\mathrm{T}$ of the system is equal to the sum of kinetic energies of the two bodies, the flat car and the container:

$$
T=T_{\Pi}+T_{K}
$$

where $T_{\Pi}$ is the kinetic energy of the flat car, $T_{K}$ is the kinetic energy of the container, which are, respectively:

$$
\begin{gathered}
T_{\Pi}=\frac{m_{\Pi} \dot{x}^{2}}{2} ; \\
T_{K}=\frac{m_{K}\left(\dot{x}_{K}^{2}+\dot{y}_{K}^{2}\right)}{2}+\frac{I_{K} \dot{\varphi}^{2}}{2} .
\end{gathered}
$$

The displacements of the center of gravity of the container are:

$$
x_{k}=x+r_{k} \cos \left(\varphi_{r k}+\varphi\right)
$$




$$
y_{k}=r_{k} \sin \left(\varphi_{r k}+\varphi\right)
$$

The respective velocities are:

$$
\begin{gathered}
\dot{x}_{k}=\dot{x}-\dot{\varphi} r_{k} \sin \left(\varphi_{r k}+\varphi\right) ; \\
\dot{y}_{k}=\dot{\varphi} r_{k} \cos \left(\varphi_{r k}+\varphi\right) .
\end{gathered}
$$

Substitution of these expressions into (Eq. 5) results in

$$
T_{K}=\frac{m_{K}}{2}\left(\dot{x}^{2}-2 \dot{x} \dot{\varphi} r_{k} \sin \left(\varphi_{r k}+\varphi\right)+\dot{\varphi}^{2} r_{k}^{2}\right)+\frac{I_{k}}{2} \dot{\varphi}^{2}
$$

The total kinetic energy of the system is

$$
T=\frac{\dot{x}}{2}\left(m_{\Pi}+m_{K}\right)+\frac{\dot{\varphi}^{2}}{2}\left(m_{K} r_{k}^{2}+I_{k}\right)-m_{K} r_{k} \dot{x} \dot{\varphi} \sin \left(\varphi_{r k}+\varphi\right) .
$$

The differentiating of the kinetic energy by generalized coordinates $x, \varphi$ and generalized velocities $\dot{x}, \dot{\varphi}$ results in:

$$
\begin{aligned}
& \frac{\partial T}{\partial x}=0 \\
& \frac{\partial T}{\partial \varphi}=-m_{K} r_{k} \dot{x} \dot{\varphi} \cos \left(\varphi_{r k}+\varphi\right) ; \\
& \frac{\partial T}{\partial \dot{x}}=\dot{x}\left(m_{\Pi}+m_{K}\right)-m_{K} r_{k} \dot{\varphi} \sin \left(\varphi_{r k}+\varphi\right) ; \\
& \frac{\partial T}{\partial \dot{\varphi}}=\dot{\varphi}\left(m_{K} r_{k}^{2}+I_{k}\right)-m_{K} r_{k} \dot{x} \sin \left(\varphi_{r k}+\varphi\right) .
\end{aligned}
$$

The time derivatives:

$$
\begin{aligned}
& \frac{d}{d t}\left(\frac{\partial T}{\partial \dot{x}}\right)=\ddot{x}\left(m_{I I}+m_{K}\right)-\ddot{\varphi} m_{K} r_{k} \sin \left(\varphi_{r k}+\varphi\right)-\dot{\varphi}^{2} m_{K} r_{k} \cos \left(\varphi_{r k}+\varphi\right) ; \\
& \frac{d}{d t}\left(\frac{\partial T}{\partial \dot{\varphi}}\right)=\ddot{\varphi}\left(m_{K} r_{k}^{2}+I_{k}\right)-\ddot{x} m_{K} r_{k} \sin \left(\varphi_{r k}+\varphi\right)-\dot{x} \dot{\varphi} m_{K} r_{k} \cos \left(\varphi_{r k}+\varphi\right) .
\end{aligned}
$$

The generalized forces along the coordinates $x$ and $\varphi$ : 


$$
\begin{aligned}
& Q_{x}=P(t) ; \\
& Q_{\varphi}=m_{K} g r_{k} \cos \left(\varphi_{r k}+\varphi\right) .
\end{aligned}
$$

Substituting of these relationships into (Eq. 2) results in equations:

$$
\begin{aligned}
& \ddot{x}\left(m_{\Pi}+m_{K}\right)-\ddot{\varphi} m_{K} r_{k} \sin \left(\varphi_{r k}+\varphi\right)-\dot{\varphi}^{2} m_{K} r_{k} \cos \left(\varphi_{r k}+\varphi\right)=P(t) ; \\
& \ddot{x} m_{K} r_{k} \sin \left(\varphi_{r k}+\varphi\right)-\ddot{\varphi}\left(m_{K} r_{k}^{2}+I_{k}\right)=m_{K} r_{k} g \cos \left(\varphi_{r k}+\varphi\right) .
\end{aligned}
$$

It may be noted that equations (Eq. 6) characterize the dynamic equilibrium, the first is equilibrium equation of forces in the longitudinal direction, the second - equilibrium of the moments caused by rotation of the container.

Since the angle of the container rotation cannot be negative, the following restriction may be suggested that fittings are supported at the car structure by the rigid springs. With this suggestion the right-hand part of second equation in (Eq. 10) may be written as:

$$
M=\left\{\begin{array}{l}
m_{K} r_{K} g \cos \left(\varphi_{r k}-\varphi\right) n p u \varphi>0 ; \\
0 \text { nрu } \varphi=0 ; \\
m_{K} r_{K} g \cos \left(\varphi_{r k}-\varphi\right)-K_{\varphi} \varphi \text { прu } \varphi<0 .
\end{array}\right.
$$

Any of the known numerical methods can be applied to solve the system (Eq. 10). Solving (Eq. 10) relatively $\ddot{x}$ and $\ddot{\varphi}$, by taking into account (Eq. 11), results in following equations:

$$
\begin{gathered}
\ddot{x}=\frac{\left(P(t)+\dot{\varphi}^{2} m_{K} r_{k} \cos \left(\varphi_{r k}+\varphi\right)\right)\left(m_{K} r_{k}^{2}+I_{k}\right)-M m_{K} r_{k} \sin \left(\varphi_{r k}+\varphi\right)}{\left(m_{\Pi}+m_{K}\right)\left(m_{K} r_{k}^{2}+I_{k}\right)-m_{K}^{2} r_{k}^{2} \sin ^{2}\left(\varphi_{r k}+\varphi\right)} ; \\
\ddot{\varphi}=\frac{M\left(m_{I I}+m_{K}\right)-\left(P(t)+\dot{\varphi}^{2} m_{K} r_{k} \cos \left(\varphi_{r k}+\varphi\right)\right) m_{K} r_{k} \sin \left(\varphi_{r k}+\varphi\right)}{\left(m_{I I}+m_{K}\right)\left(m_{K} r_{k}^{2}+I_{k}\right)-m_{K}^{2} r_{k}^{2} \sin ^{2}\left(\varphi_{r k}+\varphi\right)} .
\end{gathered}
$$

The three versions of the longitudinal loading on the flat car may be considered:

1) permanent load $P(t)=3.5 \mathrm{MN}$;

2) linearly increasing loading;

3) the loading caused by collision of the cars equipped with the absorbing devices of the T1-class [13-15].

Firstly, the following example is analyzed:

- the mass of flat car is taken as $m_{\Pi}=22.0 \mathrm{t}$;

- the mass of 20-foot container is $m_{K}=24.0 \mathrm{t}$;

- the distance from the fitting to the container center of gravity is $r_{K}=3.2 \mathrm{~m}$;

- the container turning angle is $\varphi_{r K}=24^{\circ}$. 


\section{TPACEE-2016}

Fig. 3 shows displacement and velocity of the flat car, and displacement of the center of gravity of the system flat car - container installed on it. Fig. 4 illustrates the time-dependent turning angle and angular velocity of the container.

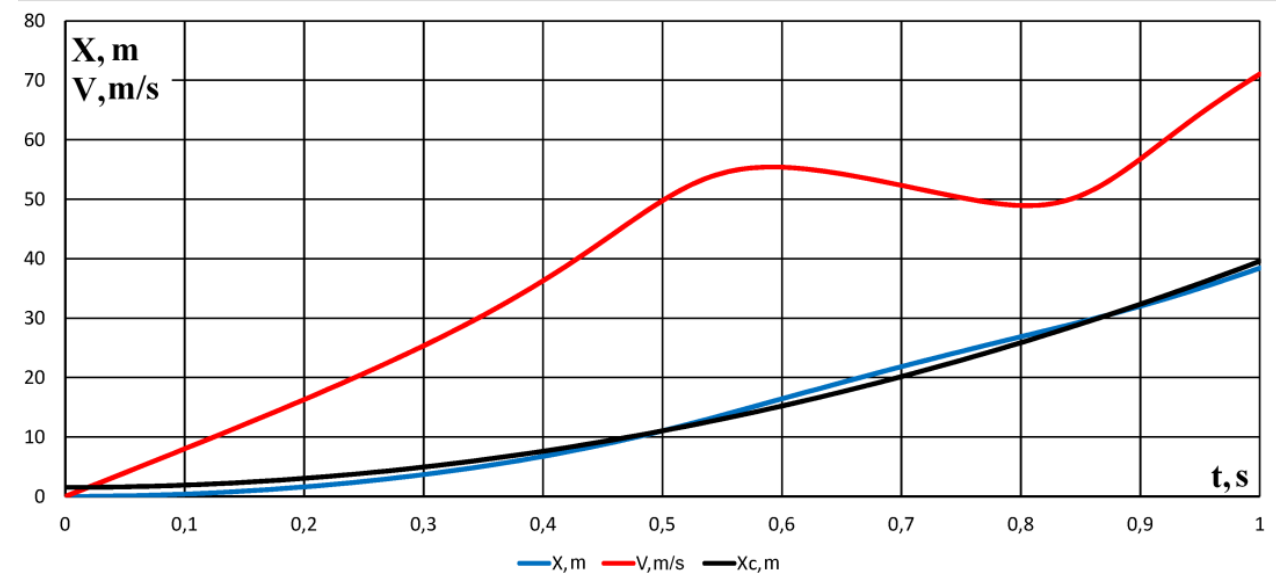

Fig. 3. Time-dependent displacement of the center of mass and of velocity of the flat car, and displacement of the center of mass of the system flat car-container.

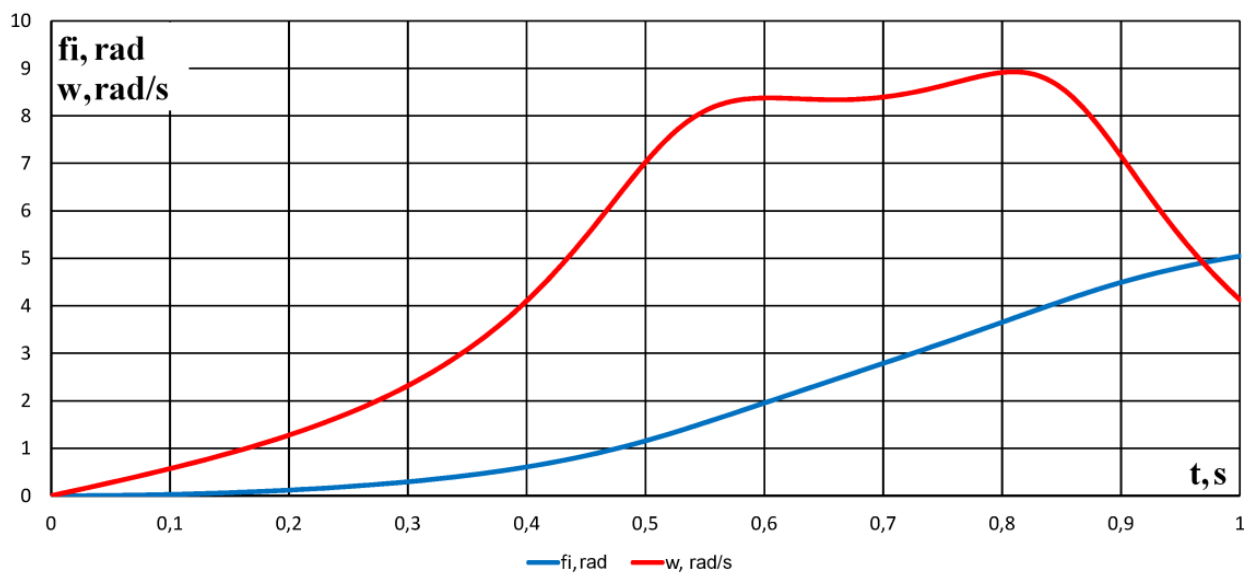

Fig. 4. Dependence in time of the rotation angle and angular velocity of the container with respect to the fitting from the side of impact.

As seen from Fig. 4, incase of application of the permanent load equal to $3.5 \mathrm{MN}$ the container will inevitably overturn already through $0.5 \mathrm{sec}$.

From practice it is known that at impacts of cars it takes no more than 0.2 second that the longitudinal loading would reach the peak value $[16,17]$. Therefore the linearly increasing loading case is considered.

In the second loading case the force applied to the car frame can be defined by the following relationships: 


$$
P(t)=\left\{\begin{array}{l}
\frac{P_{\max }}{t_{1}} t \text { at } 0 \leq t \leq t_{1} ; \\
P_{\max }-\frac{P_{\max }}{t_{2}-t_{1}}\left(t-t_{1}\right) \text { at } t_{1}<t \leq t_{2} \\
0 \text { at } t>t_{2},
\end{array}\right.
$$

where $t_{1}$ is the time through which the loading reaches a peak value; it is assumed that $t_{1}=0.2 \mathrm{~s} ; t_{2}$ is the time for which loading from a maximum value drops down to zero; it is take as $t_{2}=0.05 \mathrm{~s}$.

Fig. 5 shows the time dependence of the displacement and velocity of the flat car, and also displacement of the center of gravity of the flat car - container system.

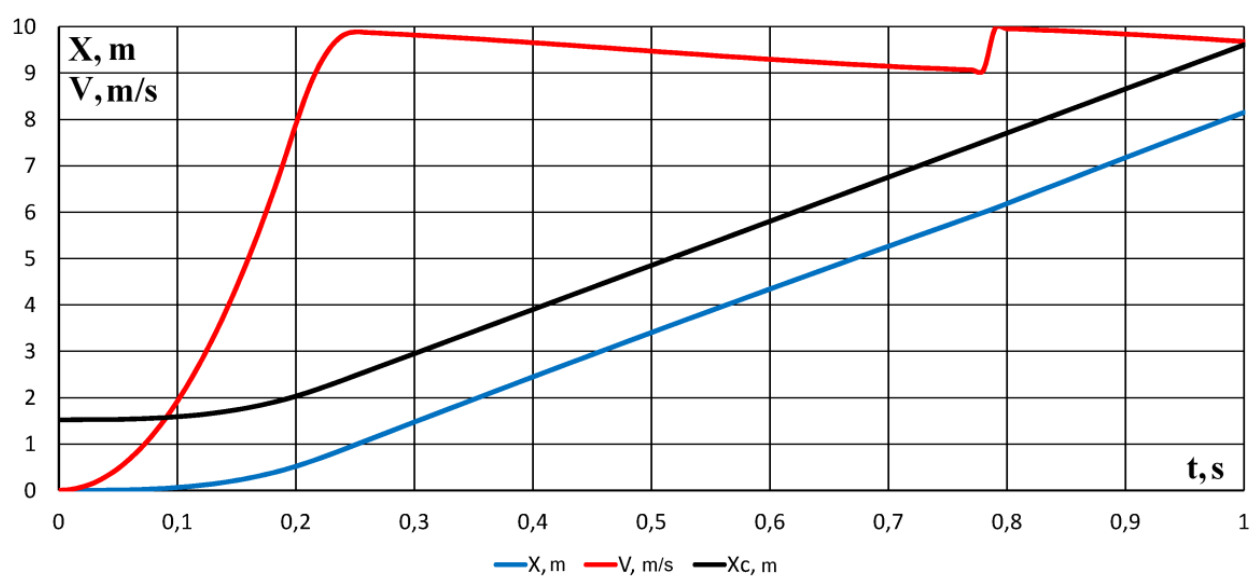

Fig. 5. The time dependence of the displacement of the center of gravity and velocity of the flat car, and of the displacement of the center of mass of the system flat car-container.

In Fig. 6 the time dependence of the rotation angle and angular velocity of the container are shown. Fig. 6 shows that the maximum angle of rotation of the container reaches $\varphi_{\max }=0.10190 \mathrm{rad}=5.8386^{\circ}$. Maximum height which would reach the container fitting from the side opposite to the impact would be around $h_{\max }=\sin \left(\varphi_{\max }\right) \cdot L=\sin (0.013881) \cdot 6=0.610 \mathrm{~m}$. So far, at the normative impact loads transferred through the automatic coupling the container by no means can overturn.

A more realistic result may be found if a case of collision of two cars equipped with the elastic-frictional absorbing class T1 devices would be considered [18, 19]. The mathematical model of the device is described in [20]. The scheme of the process of collision of cars is given in Fig. 7. 


\section{TPACEE-2016}

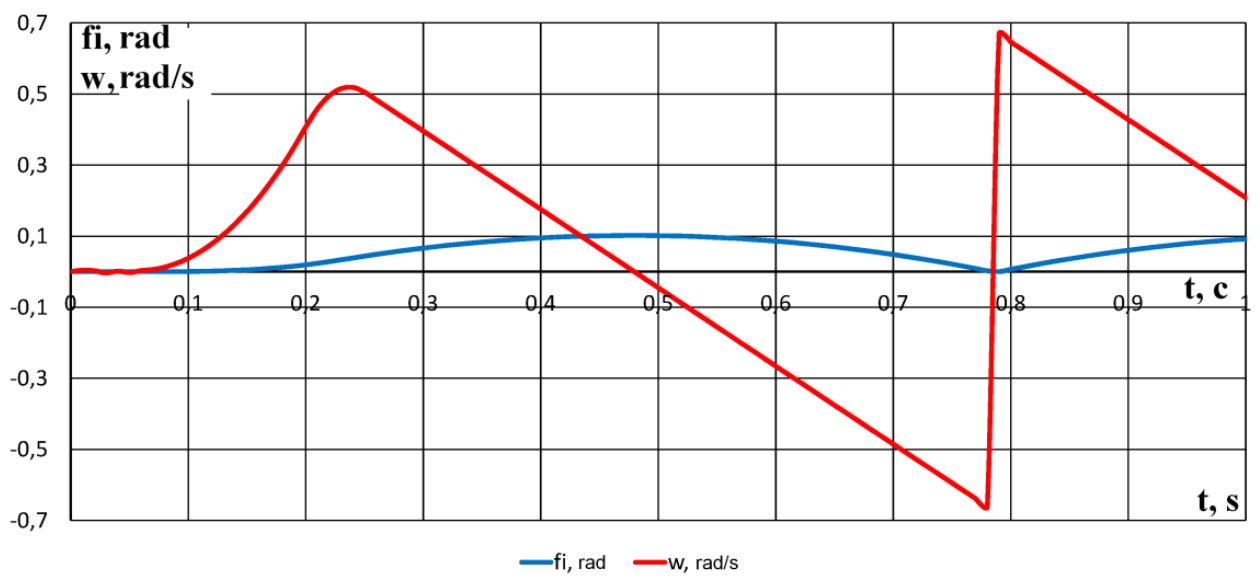

Fig. 6. The time dependence of the rotation angle and angular velocity of the container relative to fitting from the side of impact.

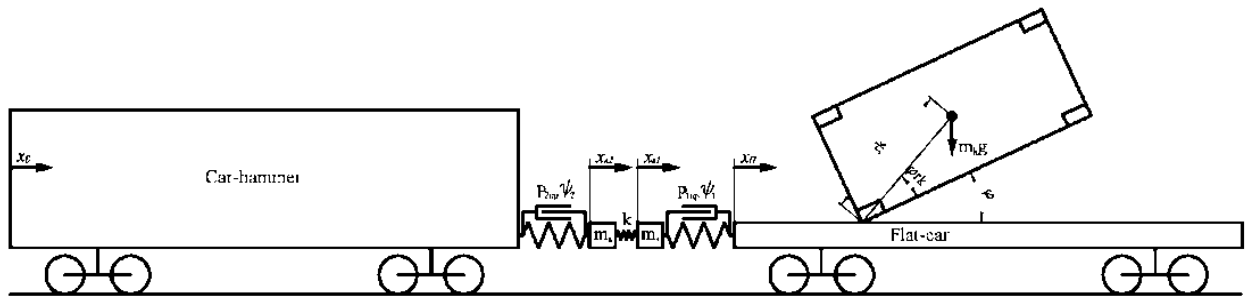

Fig. 7. Scheme of dynamic coupling of cars.

Equations of displacements of this system are as follows:

$$
\begin{aligned}
& \ddot{x}_{I I}\left(m_{\Pi}+m_{K}\right)-\ddot{\varphi} m_{K} r_{k} \sin \left(\varphi_{r k}+\varphi\right)-\dot{\varphi}^{2} m_{K} r_{k} \cos \left(\varphi_{r k}+\varphi\right)-\psi_{1} P_{n p 1} \operatorname{sign}\left(x_{a 1}-x_{\Pi}\right)=0 \\
& \ddot{x}_{I I} m_{K} r_{k} \sin \left(\varphi_{r k}+\varphi\right)-\ddot{\varphi}\left(m_{K} r_{k}^{2}+I_{k}\right)-M=0 \\
& m_{a} \ddot{x}_{a 1}+\psi_{1} P_{n p 1} \operatorname{sign}\left(x_{a 1}-x_{I}\right)-k\left(x_{a 2}-x_{a 1}\right)=0 \\
& m_{a} \ddot{x}_{a 2}+k\left(x_{a 2}-x_{a 1}\right)-\psi_{2} P_{n p 2} \operatorname{sign}\left(x_{5}-x_{a 2}\right)=0 \\
& m_{b} \ddot{x}_{b}+\psi_{2} P_{n p 2} \operatorname{sign}\left(x_{5}-x_{a 2}\right)=0
\end{aligned}
$$

where $\quad \psi_{1}$ is the transfer coefficient of the wedge system of the damping device of the flat car; $P_{n p 1}$ is the compression force of the supporting block of the damping device of the flat car; $\psi_{2}$ is the transfer coefficient of the wedge system of the damping device of the carhammer; $P_{n p 2}$ is the compression force of the supporting block of the damping device of the car-hammer; $m_{a}$ is the mass of the movable parts of automatic coupler; $k$ is the longitudinal stiffness of the connected bodies of automatic couplers; $m_{b}$ is the mass of the car-hammer.

The directions of forces applied by the container to the flat car fitting from the side of impact are shown in Fig. 8.

$$
\vec{R}=\vec{R}_{x}+\vec{R}_{y}+\vec{R}_{r}+\vec{R}_{\tau}
$$

The values of these forces can be obtained by formulae: 


$$
R_{x}=m_{K} \ddot{x} ; \quad R_{y}=m_{K} g ; \quad R_{r}=m_{K} \dot{\phi}^{2} r_{k} ; \quad R_{\tau}=m_{K} \ddot{\phi} r_{k} .
$$

The projections of the total force $R$ on horizontal and vertical axes:

$$
\left\{\begin{array}{l}
\sum R_{x}=m_{K} \ddot{x}-m_{K} \dot{\varphi}^{2} r_{k} \cos \left(\varphi_{r k}+\varphi\right)-m_{K} \ddot{\varphi} r_{k} \sin \left(\varphi_{r k}+\varphi\right) ; \\
\sum R_{y}=m_{K} g-m_{K} \dot{\varphi}^{2} r_{k} \sin \left(\varphi_{r k}+\varphi\right)+m_{K} \ddot{\varphi} r_{k} \cos \left(\varphi_{r k}+\varphi\right) .
\end{array}\right.
$$

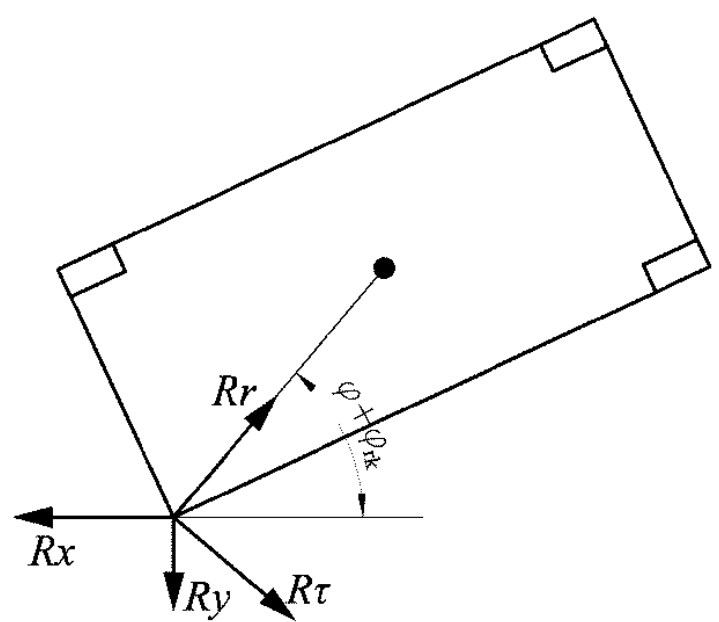

Fig. 8. The forces of interaction between the flat car and the container.

The variation in time of the vertical component of the interaction force between the fitting of flat car and container from the side of impact is presented in Fig. 9.

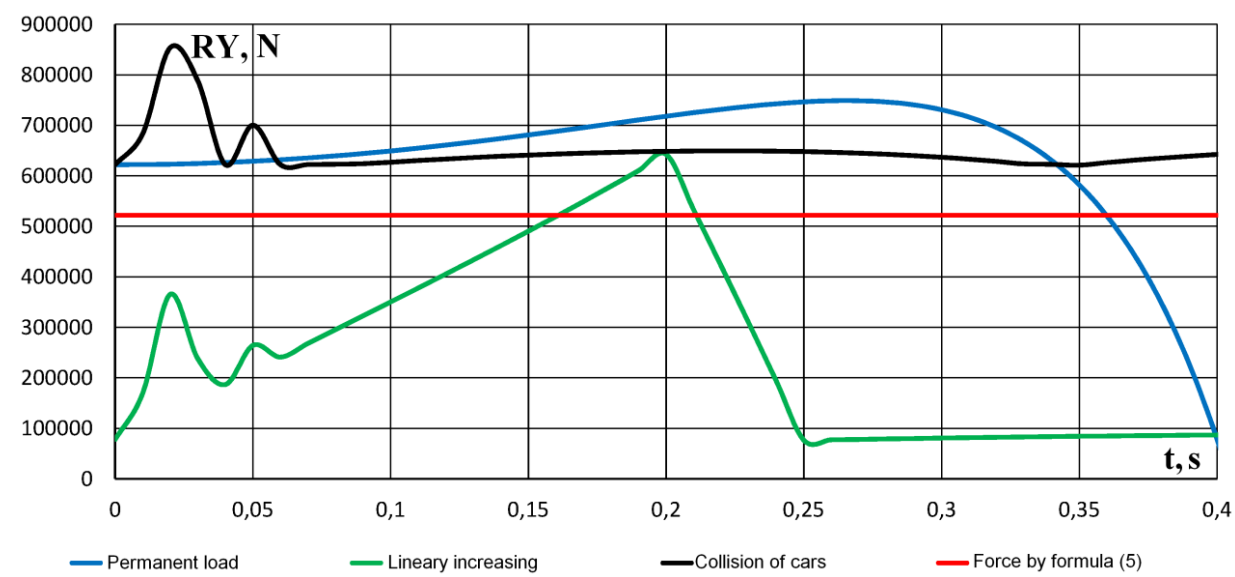

Fig. 9. Change in time of vertical force of interaction between the fitting of flat car and container from the side of impact.

\section{Conclusions}

It is seen from Fig. 9 that the load determined by (Eq. 5) is not overestimated and it can be applied for static strength analysis. 
For the more detailed solution of the flat car-container system behavior it is necessary to develop model in which flexibility of spring suspension of a flat car would be considered. Also, the full-scale tests should be carried out with registration of forces on fittings and displacements of the container with respect to the flat car; the results of tests and of the analysis further should be compared.

The reported study was funded by RFBR according to the research project №16-08-00845a «Verification and development of models of inelastic deformation at the passive loading». The authors declare that there is no conflict of interest regarding the publication of this paper.

\section{References}

1. B. Melnikov, A. Semenov, Applied Mechanics and Materials, 617, 187-192 (2014)

2. Normy dlya rascheta i projektirovaniya vagonov zheleznyh dorog MPS kolei $1520 \mathrm{~mm}$ (nesamohodnyh) (GosNIIV, VNIIZHT, 1996)

3. Nabeel S. Gharaibeh, Mohammed I. Matarneh, V.G. Artyukh, Research Journal of Applied Sciences, Engineering and Technology, 8(12), 1461-1464 (2014)

4. V.G. Artiukh, Nagruzki i peregruzki v metallurgicheskih mashinah (PSTU, Mariupol, 2008)

5. V.G. Artiukh, Basis of Protection of Metallurgical Machines from Breakdown (Publishing Group "University", Mariupol, 2015)

6. V. Mazur, V. Artyukh, G. Artyukh, M. Takadzhi, Engineering Designer, 37(1), 26-29 (2012)

7. Mohammed I. Matarneh, Nabeel S. Gharaibeh, V. G. Artyukh, International Journal of Engineering Science and Innovative Technology, 4(2), 1-7 (2015)

8. V.G. Artiukh, Tochnost predohranitelei dlia metallurgicheskih mashin (PSTU, Mariupol, 2000)

9. A.A. Alyamovskiy, SolidWorks/COSMOSWorks. Engineering FEM analysis (DMK Press, 2004)

10. V. Sevastyanov, A. Volvach, Computer design and technical flow of documents, 2, 28-31 (2007)

11. A.B. Kaplun, E.M. Morozov, M.A. Olferieva, ANSYS in Engineer's Hands. Practical issue (Editorial URSS, 2003)

12. SIMULIA Abacus (CAE User's manual), V.6.7 (2008)

13. G.V. Artiukh, V.G. Artiukh, V.A. Korchagin, T.V. Korchagina, Ukraine Patent 82,142 (2007)

14. G.V. Artiukh, V.G. Artiukh, V.A. Korchagin, T.V. Korchagina, Ukraine Patent $\mathbf{8 5 , 9 6 2}(2009)$

15. G.V. Artiukh, V.G. Artiukh, V.A. Korchagin, T.V. Korchagina, Russia Patent $\mathbf{2 , 3 7 3 , 0 9 2}$ (2009)

16. G.V. Artiukh, V.G. Artiukh, E.I. Ivanov, Protection of Metallurgical Machines from Breakdowns, 15, 150-155 (2013)

17. Firas M.F. Al-Quran, M.E. Matarneh, V.G. Artukh, Research Journal of Applied Sciences, Engineering and Technology, 4(11), 1585-1589 (2012)

18. B.E. Melnikov, L.F. Khazieva, Advanced Materials Research, 915-915, 68-71 (2014)

19. V.G. Artiukh, S.Yu. Karlushin, E.N. Sorochan, Procedia Engineering, 117, 938-944 (2015)

20. S.V. Myamlin, N.E. Naumenko, A.A. Nikitchenko, Vestnik DIIT, 24, 25-33 (2008) 